\title{
Analysis of a Waste Heat Recovery System for a Gas Engine
}

\author{
Chen Bo \\ North University of China, Taiyuan, China, 030051 \\ China North Engine Research Institute (Tianjin), Tianjin, China, 300400
}

Wang Genquan \& Zhang Limin

China North Engine Research Institute (Tianjin), Tianjin, China, 300400

Wang Xuan \& Liu Peng
Tianjin University, Tianjin 300072, China

ABSTRACT: Internal combustion engines are applied in modern industry widely and consume a lot of energy at the same time. As the energy crisis and environment problem become serious, finding alternative energy and improving the efficiency of engines have been focused by the world. The gas fuel engine has been paid more and more attention to, because of its clean, high efficiency, and the development of gas fuel. A gas engine with rate power $1000 \mathrm{~kW}$ is selected as researched object in the paper. Considering about the character of its waste heat, an ORC system is proposed to improve the efficiency and the math model is built in the paper by MATLAB. The performances of ORC with different preheat source and different work fluids are studied to optimize the system. The results show that the ORC system with jacket water as low temperature preheater and high critical temperature work fluid is suitable for waste heat recovery of gas engines.

KEYWORD: Internal combustion engine, ORC, work fluid, preheater.

\section{INSTRUCTIONS}

Development of human industrial civilization is inseparable from a wide variety of power machines. In these power machines, the internal combustion engine is widely used because of its highest thermal efficiency, good fuel flexibility, high energy density, low weight per unit power, low cost and high reliability. Internal combustion engines which have more than a billion units in the world occupy the first place among all the power machines. A huge number of internal combustion engines consume a lot of energy and make a large number of pollutants every year. With crisis of energy resources and more and more serious environmental pollution problem, searching for new alternative energy of internal combustion engines and improving their efficiency have become a very important topic for all countries in the world.

Internal combustion engines which use gas resources, including conventional natural gas and unconventional natural gas as fuel are constantly on the rise. As an alternative energy resource, gas has huge potential of energy utilization and economic benefits, on the other hand it has the characters of low carbon, clean, efficient and low-pollution, so it is valued by governments and energy companies. It is estimated that the storage of the conventional natural gas resources in the world is $512.6 \times 10^{12} \mathrm{~m}^{3}$, unconventional gas resources (mainly including: tight gas (tight sandstone gas reservoirs, volcanic gas reservoirs, carbonate gas reservoirs), coal bed methane, shale gas, natural gas hydrates (commonly known as combustible ice), water-soluble gas, inorganic gas and so on) is approximately $2338.2 \times$ $10^{12} \mathrm{~m}^{3}$, which is about 3.15 times as much as the amount of conventional oil resources [1]. In addition, a gas-fired plant produces half the $\mathrm{CO}_{2}$ emissions of a coal-fired one, so the use of fuel gas resource has very important meaning to alleviate the energy crisis and environmental problems.

From the view of energy balance, the thermal efficiency of gas engines is generally less than the diesel engine, useful work accounted for about 30$40 \%$ of the total quantity of heat of input fuel in gas engines [2]. In addition to a small part of the waste heat loss to the environment, most of the waste heat is carried away by exhaust gas, jacket cooling water, charge air and so on; the exhaust gas contains a maximum of waste heat, which is approximately equal to output power, jacket water followed. Therefore, waste heat recovery of internal combustion engines is an effective way to improve the overall energy efficiency and reduce fuel consumption. International internal combustion engine industry generally considers that waste heat recovery of the internal combustion engine has the greatest potential for energy saving. At the same time, governments and enterprises have been put into research and development of the waste heat recovery of internal combustion engine [3-7]. 
There are a lot of studies about waste heat recovery of diesel engine [8-11], the gas engine is similar with the diesel engine, as well as the property of waste heat, but it also has its own characteristics. Due to the high thermal efficiency of the diesel engine compared to gas engine, the exhaust gas temperature is higher in gas engine [12], so if the exhaust gas discharges directly into the atmosphere, there is more heat released into the environment, causing a waste of energy. In addition to the difference in temperature, the exhaust gas of diesel engine has other distinct features: the acid dew point of diesel engine exhaust is generally $120-150{ }^{\circ} \mathrm{C}$ [13], in order to prevent corrosion of equipment, the temperature of exhaust gas in waste heat recovery equipment cannot be reduced below the acid dew point. Many fuel gas usually is low-sulfur , especially conventional natural gas, so for gas engine, the acid dew point of exhaust gas is low, some studies even mentioned that the exhaust gas temperature of gas engine can be unrestricted by acid dew point [12]. For gas engine, the available waste heat of exhaust gas is more than the exhaust gas of diesel engine. For these reasons, waste heat recovery of the gas engine has even more significance.

In recent years, ORC (Organic ranking cycle) is considered by many scholars as a very appropriate way for waste heat recovery of internal combustion engine [14]. This paper selects a rated power of $1100 \mathrm{~kW}$ gas engine as the research object and based on the character of its waste heat, an ORC system is built to improve its efficiency. The paper discusses the system performance with different heat source as preheat source in detail and analyzes the system performance when using different working fluids, as well as their ability to recover the energy of different preheat source.

\section{SYSTEM DESCRIPTION}

\subsection{Studied gas engine}

The studied gaseous fuel engine is used for producing electricity. Compared to engines for ships or automobiles, it has more stable working conditions. Therefore, the ORC systems for waste heat recovery are easier to apply successfully and run steadily. The rated power of the gas engine is $1100 \mathrm{~kW}$ and the corresponding output electricity power is $1000 \mathrm{~kW}$. The exhaust, jacket water and charge air of the studied engine at the rated power are heat source of the ORC for waste heat recovery. The main parameters of the waste heat are as Table.1. It should be noticed that the volume flow rate is measured in standard condition $(273 \mathrm{~K}$, $101 \mathrm{kPa}$ ).

From table 1 it can be seen that the actual air-fuel ratio is larger than theoretical air-fuel ratio. Because lean combustion makes a contribution to the fuel economy of gas engines [15-16]. As a consequence, most of gas engines on the market use large air-fuel ratio. According to the actual air-fuel ratio and assume complete combustion, the volume fraction of the exhaust gas can be get: $\mathrm{N}_{2}=74.0 \%, \mathrm{CO}_{2}=6.3 \%$, $\mathrm{H}_{2} \mathrm{O}=12.7 \%$ (gas), $\mathrm{O}_{2}=7 \%$. With this, exhaust physical properties can be obtained.

Table 1. Main parameters of engine exhaust

\begin{tabular}{|l|l|}
\hline Parameter & values \\
\hline Exhaust temperature & $532^{\circ} \mathrm{C}$ \\
\hline Exhaust pressure after turbo charger & $1.1 \mathrm{bar}$ \\
\hline Volume flow rate of intake air & $1.16 \mathrm{~m} 3 / \mathrm{s}$ \\
\hline Volume flow rate of gaseous fuel & $0.0784 \mathrm{~m} 3 / \mathrm{s}$ \\
\hline Actual air-fuel ratio (Volume ratio) & 14.8 \\
\hline Theoretical air-fuel ratio (Volume ratio) & 9.52 \\
\hline Exhaust mass flow rate (standard conditions) & $1.25 \mathrm{~m} 3 / \mathrm{s}$ \\
\hline Jacket water mass flow rate & $8.33 \mathrm{~kg} / \mathrm{s}$ \\
\hline Inlet temperature of jacket water & 66 \\
\hline Outlet temperature of jacket water & 80 \\
\hline Chair air temperature after turbo charger & $103^{\circ} \mathrm{C}$ \\
\hline
\end{tabular}

\subsection{The ORC system for waste heat recovery}

$\mathrm{ORC}$ is regarded as a very suitable way to recovery waste heat of internal combustion engines and there have been a lot of researches about that. The ORC for this gas engine consists of steam boiler, pump, low temperature preheater, high temperature preheater, evaporator, turbine and condenser as Fig.1.

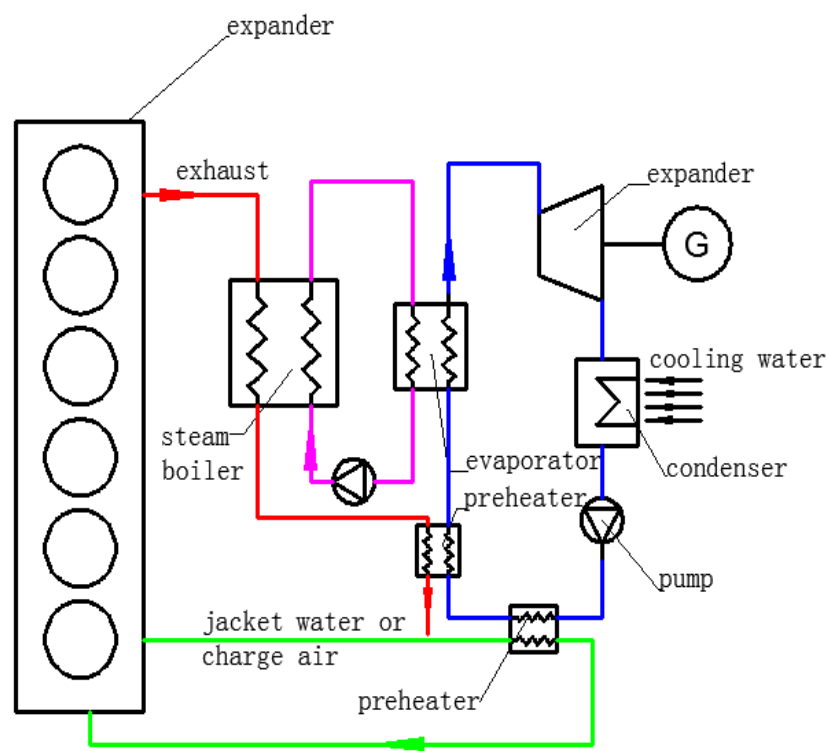

Figure.1. the schematic diagram of the waste heat recovery system

Because the temperature of exhaust is very high, if it is used to heat the organic work fluid directly, the work fluid may resolve. As a result, the exhaust is used to heat water making it become steam through a boiler, and then the organic work fluid is 
heated by the steam to form gas of high temperature and pressure. The temperature of exhaust gets down after boiler, so it can carry on preheating the work fluid. As mentioned above, the final temperature of exhaust is limited by acid dew point which depends on the constitution of gas fuel. If the acid dew point is set, the heat below it cannot be used, while jacket water or charge air can be the low temperature preheat source. The effects of different preheat source on the ORC is studied in below text. The high temperature and pressure gas enters the expander to expand, and makes work. Then the gas after expander flows into condenser in which it is cooled to saturation liquid. Finally, the work fluid is pumped to the preheater and evaporator again.

The pinch point method is used in the math model of ORC. This method is very common in many researches. The math model can refer to literature [17-18], so it is not described in the paper in detail.

\section{RESULTS AND ANALYSIS}

All the results are calculated at the environment temperature of $30^{\circ} \mathrm{C}$ and the condensing temperature of $35^{\circ} \mathrm{C}$. In the analysis below, the evaporating temperature of ORC is the variate and the corresponding saturation pressure of different work fluids are as shown in Fig.2.

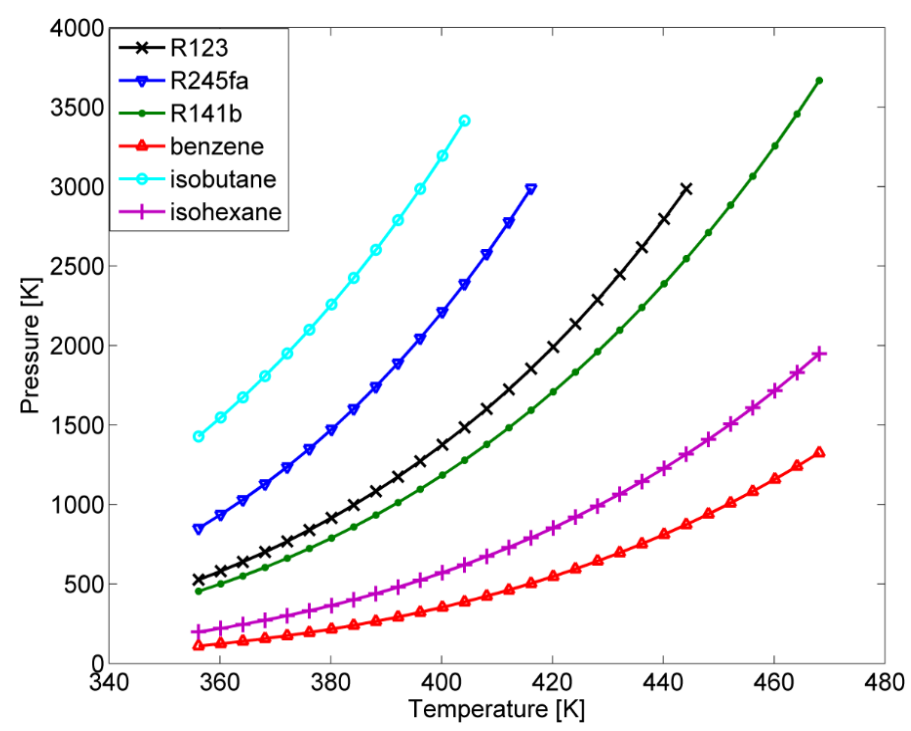

Figure.2. the saturation pressure of different work fluids at different temperature.

Fig.3 describes the output power and thermal efficiency of the ORC system with four different kinds of low temperature preheat source. The work fluid in this Fig is R123. The waste heat of the exhaust above acid dew point is used as the high temperature preheat source and evaporating source of steam boiler in all the system. The difference is that there is only one system that uses the heat of exhaust below $120^{\circ} \mathrm{C}$ (the assumed acid dew point) as low temperature preheat source and the other two use jacket water and charge air. The last one doesn't have low temperature preheater. From the Fig it can be seen that the system with jacket water preheater has the largest output power which can be about $117 \mathrm{~kW}$ at most. The other three kinds of ORC systems ranging from the largest to the smallest are the one with charge air preheater, exhaust preheater and without low temperature preheater in order. Besides, the Fig shows that the efficiencies of all systems are the same, so the more power outputs, the more heat absorbs. The heat transferred in evaporator and high temperature preheater of all systems are the same, which means that the preheat capacity of low temperature heat source decides the output power of ORC system. Compared to the system without low temperature preheater, the systems with it can not only use other waste heat of engines, but also make the output power increase and the jacket water has the most preheat capacity.

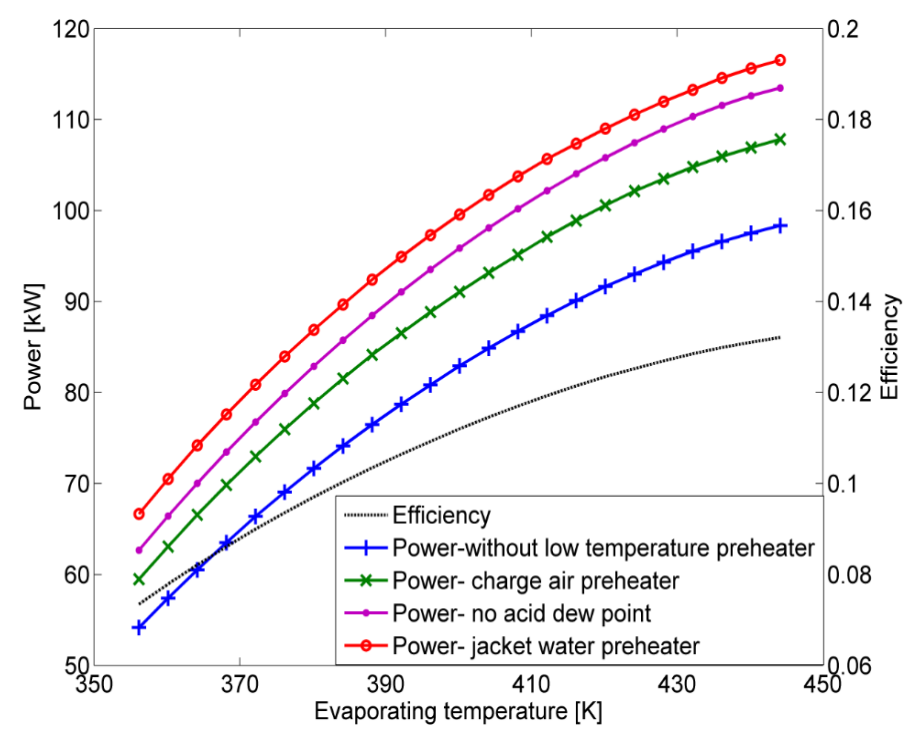

Figure.3. The output power and thermal efficiency of the ORC system with four different kinds of low temperature preheat source.

Fig.4 shows the exergy efficiency of the four systems with different low temperature preheaters. The Fig indicates that the low temperature preheater can increase the exergy efficiency. Because the addition of preheat doesn't affect thermal efficiency, while the exergy in this part is lower than that in the high temperature exhaust which means the exergy efficiency of it is higher. As a result, low temperature preheaters lead to a contribution to the whole exergy efficiency. The jacket water has the largest mass flow, the lowest temperature and the greatest preheat capacity, so the ORC with jacket water preheater has the highest exergy efficiency. In a word, using low temperature preheater can not only improve the output power, but also the exergy efficiency. It conforms to the principle of using energy according to the quality. 


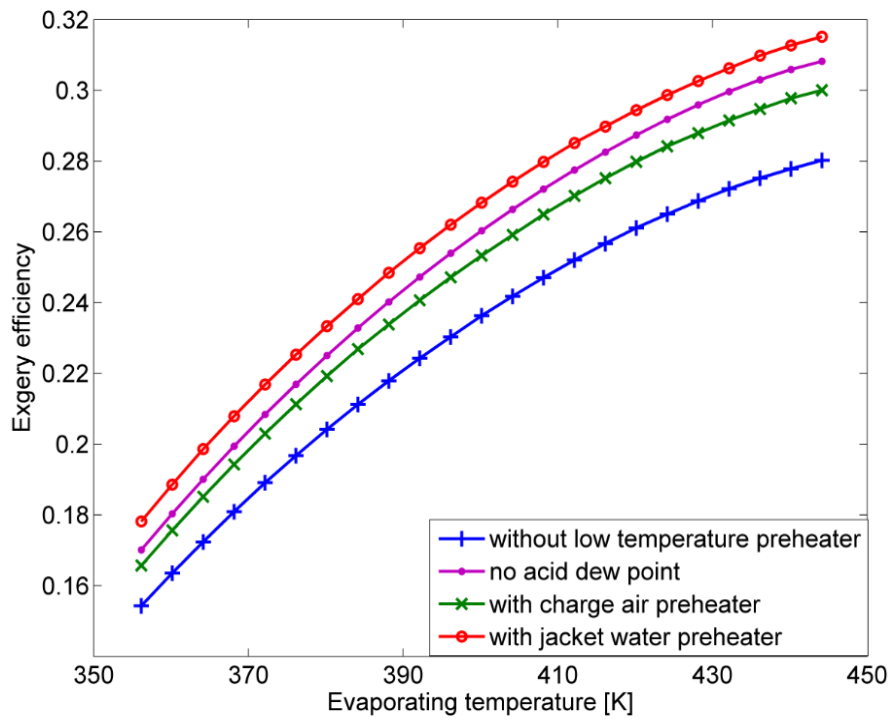

Figure.4. The exergy efficiency of the four systems with different low temperature preheaters

In order to find a suitable work fluid for the system and compare the preheat capacity of jacket water and charge air, several kinds of work fluid are selected to research. As well known, the work fluid of ORC should meet these requirements [19][20]:

1. Evaporating temperature and the corresponding saturation pressure should not be very high to avoid too much mechanical compression.

2. The work fluid mustn't resolve.

3. High enthalpy drop in expander.

4. The work fluid can be operated easily under conventional environment, so the boiling temperature should be between $0-100^{\circ} \mathrm{C}$.

5 . Good thermostability.

6. No corrosion or low corrosion resistance, nontoxic, no flammability.

7. Low cost.

8. Environmentally friendlier, low GWP and ODP.

It is very hard to find a kind of work fluid which can meet all the requirements. Refer to researches of work fluid before, six work fluids are selected as Table.2.

Table.2. the property of work fluids

\begin{tabular}{|l|l|l|l|l|l|l|}
\hline Work fluid & R123 & R245fa & R141b & benzene & Isobutene & isohexane \\
\hline Molecular weight & 153 & 134 & 116.95 & 78.1 & 58 & 86.2 \\
\hline Boiling T(K) & 300.8 & 288.3 & 305.1 & 353.22 & 261.3 & 333.4 \\
\hline Critical T (K) & 456.7 & 430.5 & 481.3 & 562 & 407.7 & 497.7 \\
\hline Critical P (MPa) & 3.66 & 3.64 & 4.21 & 4.9 & 3.63 & 3.04 \\
\hline Latent heat (kJ/kg) & 168.4 & 177.1 & 223 & 393.8 & 303.4 & 323 \\
\hline ODP & $0.02-0.06$ & 0 & 0.086 & & 0 & \\
\hline GWP & 120 & 1030 & 700 & & 3 & \\
\hline Flammable & NF & NF & NF & F & F & F \\
\hline Toxicity & N & L & N & H & L & L \\
\hline Thermal stability & Stable & Stable & Stable & Stable & Stable & Stable \\
\hline
\end{tabular}

F means flammable; NF means nonflammable; H means high Toxicity; L means low Toxicity; $\mathrm{N}$ means non Toxicity.

The output power and thermal efficiency of the ORC with jacket water preheater for different work fluids is shown in Fig.5. All the output power and thermal efficiency of the six work fluids increase with evaporating temperature of ORC. Because the ORC system in this study is subcritical cycle, the work fluids with low critical temperature cannot operate at high evaporating temperature, which leads to a small output power. Therefore, this kind of work fluids is not suitable for high temperature exhaust. Fig. 6 is the jacket water utilization rate of different work fluid. It can be seen that with increasing evaporating temperature, the jacket water utilization rate reduces. In this calculation model, the pinch point in evaporator and steam boiler is fixed, so when evaporating temperature raises, the heat of exhaust for evaporating work fluid reduces. As a result, the mass flow rate decreases, which leads to the reduction of absorbed heat from jacket water. Compared to Fig.5, it can be seen that the more power outputs, the less utilization of jacket water. Through our calculation, it is known that the mass flow rate and specific heat of jacket water are large, so its temperature variation is lower than that of exhaust, which results in the pinch point of jacket water preheater located in the inlet of water. This means that the temperatures of the six kinds of work fluid after jacket water preheat are the same. Therefore, the absorbed heat depends on the product of mass flow rate and specific heat of work fluid and the more it is, the more heat absorbs from jacket water. 


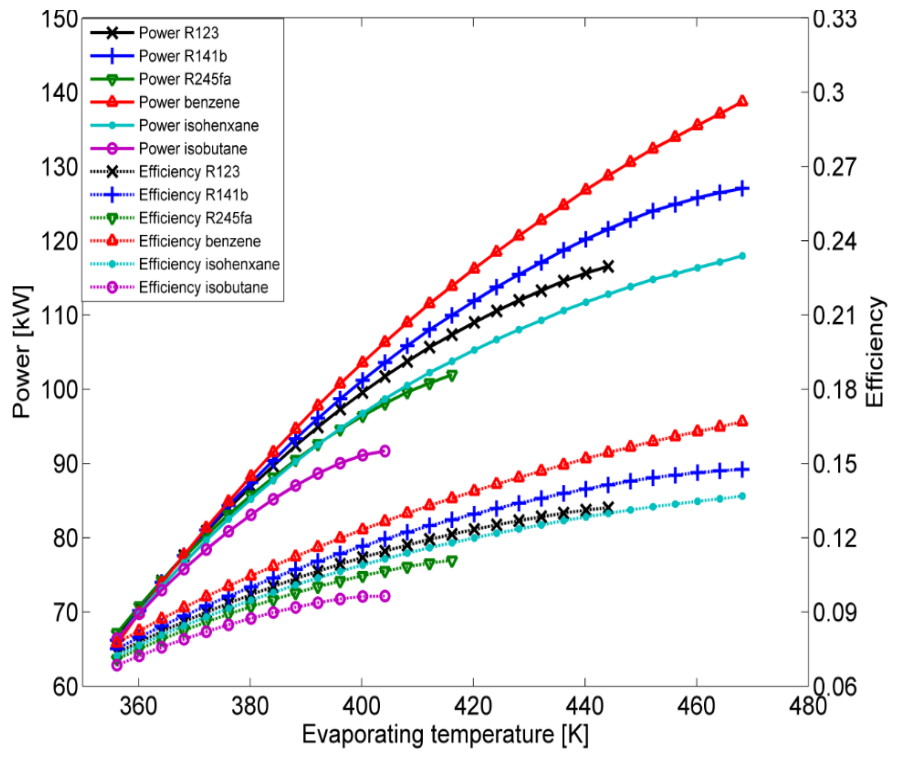

Figure 5. The output power and thermal efficiency of the ORC with jacket water preheater for different work fluids.

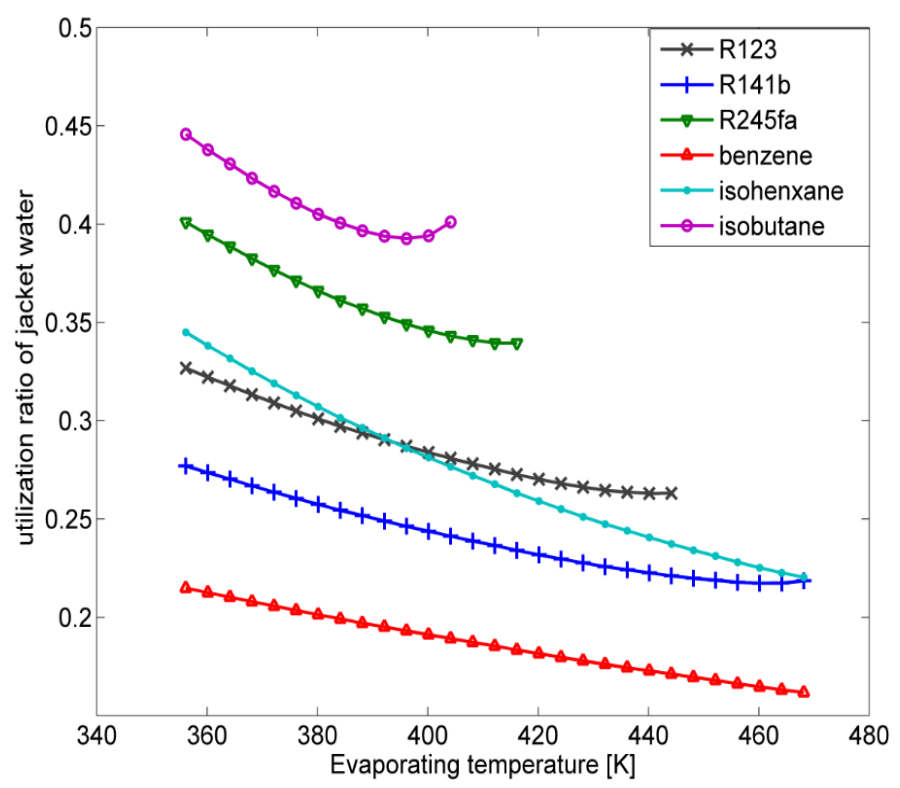

Figure 6. The jacket water utilization rate of different work fluids

If the jacket water preheater is replaced by charge air preheater, the temperature of charge air at the outlet of preheater is shown in Fig.7. The calculation results show that all the pinch points in charge air preheater for different work fluids are in the charge air outlet. In addition, the temperatures of different work fluids after pump changes a little. Therefore, the temperatures of charge air at the outlet of preheater for different work fluids are very close, and they just vary with evaporating temperature very slightly. The final temperature of charge air is about $52^{\circ} \mathrm{C}$. If the condensing temperature of ORC is lower, it will be lower than $52^{\circ} \mathrm{C}$, so the preheater can make a function of preheater.

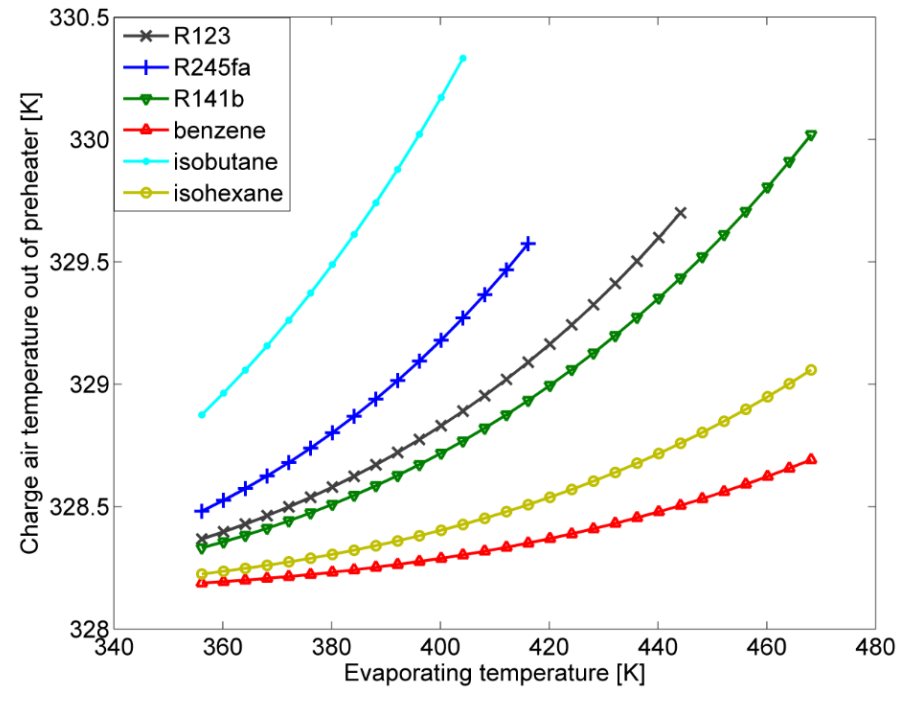

Figure 7. The temperature of charge air at the outlet of low temperature preheater.

\section{CONCLUSION}

(1) The ORC with low temperature preheat can not only use other waste heat of engines, but also make the output power and exergy efficiency increase and the jacket water has the most preheat capacity.

(2) The work fluids with low critical temperature are not suitable for high temperature exhaust to recover waste heat. Benzene has the largest output power and thermal efficiency in the six work fluids.

(3) The energy of jacket water cannot be used totally as preheat source and the most utilization rate is about 0.45 for isobutene, while its output power is the smallest.

(4) The temperatures of charge air at the outlet of preheater for different work fluids are very close and relative low.

\section{REFERENCES}

[1] Hu Wenrui. 2010. Development of unconventional natural gas: The best approach to low-carbon economy and resource efficiency. Nature gas industry, 30(9):1-8.

[2] Zhang Shengjie. 2013. Research on the Cogeneration System Based on Internal Combustion Gas Engine. Chongqing University, Master Thesis.

[3] Swami Nathan Subramanian. 2014 DOE Vehicle Technologies Program Review Heavy Duty Roots Expander Heat Energy Recovery (HD-REHER). Project ID \# ACE088, Project Start-End Date 2013.04.012014.03.31

[4] Vladimir Jovovic. Thermoelectric Waste Heat Recovery Program for Passenger Vehicles. Project ID \# ACE080. Project Start-End Date 2011.10-2015.09

[5] James R. Salvador. Cost-Competitive Advanced Thermoelectric Generators for Direct Conversion of Vehicle Waste Heat into Useful Electrical Power. Project ID \# ACE081. Project Start-End Date 2012.09-2016.09

[6] Martin Cleary. Nanostructured High Temperature Bulk Thermoelectric Energy Conversion for Efficient Waste 
Heat Recovery. Project ID \#ACE082. Project Start-End Date 2011.10-2015.09

[7] A. A. Wereszczak. Transport Properties, Thermal Response, and Mechanical Reliability of Thermoelectric Materials and Devices for Automotive Waste Heat Recovery. Project ID: pm012_wereszczak_2013_o. Project Start-End Date 2006.10-2013.11

[8] António Domingues, 2013. Analysis of vehicle exhaust waste heat recovery potential using a Rankine cycle, Energy 49:71-85.

[9] He M, Zhang X, Zeng K, Gao K. 2011. A combined thermodynamic cycle used for waste heat recovery of internal combustion engine. Energy, 36:6821-29.

[10] Vaja I, Gambarotta A. 2010.Internal combustion engine (ICE) bottoming with organic Rankine cycles (ORCs). Energy, 35:1084-93.

[11] Srinivasan KK, Mago PJ, Krishnan SR. 2010. Analysis of exhaust waste heat recovery from a dual fuel low temperature combustion engine using an organic Rankine cycle. Energy, 35:2387-99.

[12] Maria Jonsson. 2001. Ammonia-water bottoming cycles: a comparison between gas engines and gas diesel engines as prime movers, Energy 26:31-44.

[13] Industrial trigeneration using ammonia-water absorption refrigeration systems (AAR)
[14] Charles Sprouse, Review of organic Rankine cycles for internal combustion engine exhaust waste heat recovery, Applied Thermal Engineering 51 (2013) 711-722.

[15] Takeshi Kato, Kiyoaki Saeki, Hiroto Nishide. 2001. Development of CNG fueled engine with lean burn for small size commercial van, JSAE Review, 22:365-368.

[16] O. Badr, N. Alsayed and M. Manaf. 1998. A Parametric Study on the Lean Misfiring and Knocking Limits of Gasfueled Spark Ignition Engines, PII. Applied Thermal Engineering, 18(7): 579-594.

[17] Xuan Wang, Ge-Qun Shu, Hua Tian. 2014. Simulation and Analysis of an ORC-Desalination Combined System Driven by the Waste Heat of Charge Air at Variable Operation Conditions. 2014 SAE International.

[18] Xuan Wang, Ge-Qun Shu, Hua Tian. 2014. Simulation and Analysis of a New Desalination System Driven by the Waste Heat of Charge Air of Internal Combustion Engines for Ships. The International Heat Transfer Symposium 2014, Beijing.

[19] Guoquan Qiu. 2012. Selection of working fluids for micro-CHP systems with ORC. Renewable Energy, 48: 565-570.

[20] P.J. Mago, L.M. Chamra, K. Srinivasan, C. Somayaji. 2008. An examination of regenerative organic Rankine cycles using dry fluids. Applied Thermal Engineering, 28(8-9): 998-1007. 